\title{
African American Spirituality, Grief \& Mental Health: Seeking the Church After a Family Member's Violent Death
}

Author ORCID: https://orcid.org/0000-0001-7238-2755

Author Affiliation: Diane M. Chandler, PhD, Capella University

SC Classification Genre(s): Religion/Spirituality, Mental Health

Citation: Chandler, D. M. (2020). African American spirituality, grief \& mental health: seeking the church after a family member's violent death. Scholar Chatter, 1(1), 8-21, https://doi.org/10.47036/SC.1.1.8-21.2020

Creative Commons Attribution cc)

(C) The Author. 2020. This is an open access publication through Scholar Chatter LLC.

\begin{abstract}
The findings in this paper reveals and summarizes the described experience of African American adults who have sought the church for support, versus traditional mental health resources, after the violent death of a family member. The research sought to close the gap in the literature on the mental health help-seeking disparities of African American adults, in general, and confirm the importance of mental health clinicians in seeking resolutions and a deeper understanding and higher levels of cultural and spiritual competency into the mental health treatments of the African American adult population. Through a generic qualitative design and the theoretical lens of Pargament's theory of religious coping, the research question, "What are the described experiences of African American adults who seek the church after the violent death of a family member?" was answered. Ten African American adults were interviewed. Four specific themes after a thematic analysis were: (a) guidance in grief; (b) a resource for trust and relationships; (c) relationships for wisdom, direction, and support; and (d) cultural and familial traditions.
\end{abstract}

Keywords: African Americans, religion, mental health, grief, spirituality 


\section{Introduction}

About 815,000 African American adults had a serious mental illness in 2017. However, half of those adults did not obtain mental health treatment or counseling and instead sought the church for support (K. Hays \& Lincoln, 2017). Research has indicated that instead of formal mental health service providers, African Americans rely on more informal sources of support in grief, such as church and church family (Cai \& Robst, 2016; K. Hays \& Aranda, 2016; Holt et al., 2017; Jones et al., 2018; Watlington \& Murphy, 2016). A gap in the literature existed regarding the described experience of the African American adult who seeks the church for support through religion and spirituality after the violent death of a family member (Gonzalez et al., 2009; Park et al., 2018; Robinson et al., 2018; Wilson et al., 2014).

\section{Literature Review}

Throughout the literature it is also noted that African Americans' preferences for informal resources such as guidance and support of their mental health needs from the church, noting that within African American communities, church, church members, and clergy are trusted and are often sought after informal resources (K. Hays \& Lincoln, 2017; Park et al., 2018). The literature supports that African Americans have lower rates of seeking mental health services than White Americans; however, there is a gap in the research of how the African American adult population describes the experience of seeking the church for support after the violent death of a family member (Avent \& Cashwell, 2015; Morrison \& Hopkins, 2019). What remained to be understood was the described experience of the African American adult population's helpseeking behaviors seeking support from the church after the death of a family member from violence; so their mental health needs and effective treatment are understood by mental health professionals and educators (Chandler, 2020). The review of the literature for this research study has revealed several constructs:

\section{The Use of Religion and Spirituality is a Means of Coping and Resilience by African Americans}

As spirituality and religion play important parts in the lives of African American adults, the church is one place of comfort as resiliency and support is sought (Chaney, 2015; Cunningham et al., 2018; K. Hays \& Lincoln, 2017; VanderWeele et al., 2017; Wilson et al., 2014). African Americans have found the use of coping spiritually as a means of maintaining a connection to deceased family members (Avent \& Cashwell, 2015; VanderWeele et al., 2017). Other researchers have also found that aggregate adapting and thinking about others and covering of feelings were normal (Chandler, 2020; K. Hays \& Lincoln, 2017; Jones et al., 2018; Morrison \& Hopkins, 2019; Park et al., 2018; Robinson et al., 2018; Sargent et al., 2019).

\section{There are Historical Connections of Religion and Spirituality for the African American Population}

For years, the churches have had important roles as community support systems (Robinson et al., 2018). The literature supports the fact that this is particularly true for African Americans who have historically sought solace from oppression in their religion and spirituality long before clinical counselors and psychologists (Banerjee \& Canda, 2009; Cunningham et al., 2018; Johnson et al., 2015; Jones et al., 2018; K. Hays \& Aranda, 2016; Robinson et al., 2018; 
Sargent et al., 2019). The first African American churches were often kept secret, and slaves attended church meetings held at the church under a watchful eye of the overseer, or with the permission of slave masters on plantations by approved pastors (Johnson, Elbert-Avila, \& Tulsky, 2015). It is from these quite humble beginnings that some freed slaves slowly began to establish denominations specifically for African Americans, while others joined White denominations, which provided African American churches to be established (Johnson et al., 2015).

\section{The Importance of Spiritual and Cultural Competency on the Mental Health Counseling and Education Profession Exists}

One's spiritual or religious beliefs are commonly viewed worldwide; at least $90 \%$ of the United States' population reports being involved in some form of spiritual or religious practice (Sargent et al., 2019). Repeated studies on counselor self-perceived competence in addressing spirituality and religion in session yielded an overall consensus of inadequacy and feelings of a lack of preparation in their education programs (Sargent et al., 2019). Whether the progression was positive or negative towards cultural competence, it was the consensus in all of the reviewed literature that incorporating spiritual and religious matters in counseling has been slow and long overdue (Cai \& Robst, 2016). It is incumbent upon counselors to assess their personal views, recognize barriers, and increase education, particularly its systemic and treatment implications in working with African Americans who choose to seek resiliency and coping skills from the church, after the death of a family member by violence (Holt et al., 2017). As churches and community health centers respond to eliminating systemic causes of violence in a variety of ways, the information gained from this study might also assist mental health practitioners, from an educational and cultural/spiritual competency perspective, in the treatment of African Americans in the community, by evaluating the role that spirituality and religious beliefs play.

\section{There is a Possible Link Between the Under-Utilization of Traditional Mental Health Resources and a Lack of Trust for the African American Population}

The American Psychiatric Association (APA, 2017) reported that only one in three African Americans who need mental health treatment after experiencing loss and grief receives it, utilizing these services at lower rates than non-Hispanic Whites. Dalencour et al. (2017) noted that between 2008 and 2012, approximately 30\% of African Americans with a mental illness, for example, depression and PTSD, utilized mental health services to treat their conditions. Perhaps the low statistical representation of African Americans in the field of psychology and counseling, the documented increase in mental health needs of this diverse population, and the historical connections between African Americans and their spirituality and religion, accounts for where and how this population seeks guidance after experiencing grief (Jones et al., 2018; Turner et al., 2019). When Africans were first brought into their native lands to America, they were often not seen as human beings, but as slaves. From the perspective of the medical community, as a whole, many African Americans suffered at the hands of medical providers with racial discrimination concerns, and two examples of these are the Tuskegee experiment and the case of Henrietta Lacks (Skloot, 2015). The Tuskegee study, initially called the "Tuskegee Study of Untreated Syphilis in the Negro Male," was scheduled to last no longer than six months; instead, the study began in 1932 and ended 40 years later (Skloot, 2015). 


\section{A Strong Role of Religion and Spirituality on the African American Community in Coping With Grief Exists}

There is a significant level of clinical distress found in bereaved family members of violent-death victims; many have reported enduring psychological, familial, and health consequences following the death of a family member (Cacciatore et al., 2014; Cunningham et al., 2018). African Americans are less likely than any other racial and ethnic group, particularly those where there is a significant amount of community violence, to attend counseling services; they, instead, live with more severe conditions because these matters remain unaddressed (Fripp \& Carlson, 2017; NAMI, 2018). The American Psychiatric Association (APA, 2017) reported that only one in three African Americans who need mental health treatment after grief receives it, utilizing these services at lower rates than non-Hispanic Whites. There are culturally specific perspectives on the management of grief among African American families (Cai \& Robst, 2016; Holt et al., 2017). Grieving patterns of African Americans often include reliance on spiritual, collective, or shared coping resources, and the suppression of emotions to manage one's grief (K. Hays \& Lincoln, 2017; S. Johnson, Williams, \& Pickard, 2016; Katz \& Hoyt, 2014; VanderWeele et al., 2017). The literature has supported the fact that when seeking mental health care, African American church members prefer care from church members and staff, including pastors, following a religious model (Avent \& Cashwell, 2015; Cai \& Robst, 2016; Cunningham et al., 2018; Fripp \& Carlson, 2017; Gaston et al., 2016; Holt et al., 2017; Sargent et al., 2019; Skloot, 2015).

As a licensed professional counselor and a Doctor of Philosophy in Counselor Education and Supervision, I sought to inform the counseling field about treating this identified population: African American family members, who seek the church, after the death of a family member by violence (Chandler, 2020). The need has continued to exist where a better understanding of the reactions and coping behaviors of African Americans, and descriptions of their choices to seek the church after experiencing the death of a family member by violence, is needed. The researcher's motivation for the research study was cultivated many years ago, by being raised in a crime-infested neighborhood as an African American and witnessing the impact violence and crime had on the inner-city communities. The motivation also included being raised in a religious home, where my mother and father always prayed and took their life's challenges and problems to the church. As an African American woman, I was vested in describing the experiences of adult African Americans who have sought the church, and not licensed mental health professionals, after experiencing the death of a family member by violence. While attending graduate school, the researcher was exposed to many concepts of psycho-social environments and many implications that such settings may have in different cultures. As a licensed mental health professional and educator, I now also recognize that spirituality and religion do not "heal" depression or any other mental health disorders, but strongly believe religion and spirituality are important to integrate into the therapeutic process for those who have adopted these beliefs.

\section{Methodology}

The generic qualitative research design was selected as a good fit for the research topic, as it attempted to explore the African American's voice in seeking support from the church after the death of a family member due to violence and answer the research question: "What are the described experiences of African American family members who seek the church after the death of a family member by violence?" An expert review was conducted by actively practicing 
licensed mental health to ensure the instrument was credible. The sample size used for this study was 10 African Americans, aged 24-56, who sought the church after losing a family member by violence. Participants selected for the study were self-defined as religious or spiritual and sought the church versus clinical mental health resources, after the death of a family member by violence. Data collection for the study utilized semi-structured interviews through five guided interview questions (see Appendix A). Non-probability purposive sampling, with snowballing, was used by the researcher because this technique allows participants to devote their time to the research study because of their interests and strong opinions about the research conducted. The screening phone call, guided by the researcher, included specific screening questions (see Appendix A) based on the inclusion criteria. Qualified participants were invited to schedule an interview time, and the date was scheduled for the participant and the researcher. Participants were screened with eight specific questions (see Appendix B).

\section{Participant Selection}

For this generic qualitative study, participants were recruited through church bulletin announcements, church websites, and church Facebook page. Written consent from the selected church and participants was received, and Institutional Review Board approval was obtained. The semi-structured interviews were used with all selected participants, which offered a loosely structured open-ended form of questioning, and allowed the participants to explore their experiences and attitudes.

\section{Findings}

Interviews with the 10 participants indicated that their responses to grief and despair after the death of their family members by violence and seeking the church was one where guidance through their religion and spiritualty in their time of grief gave them a sense of hope and comfort. The discussion below reveals the four themes that emerged from the data collected. After a thorough thematic analysis of these results was done, several themes were constructed:

\section{Theme 1: Church Is Guidance Through Religion/ Spirituality in Grief - for Comfort and Coping}

\section{Religion and Spirituality is a Source of Coping and Resilience}

The church supports the notion that there is a significant level of clinical distress found in bereaved parents who have reported enduring psychological, familial, and health consequences following the death of a family member (Cacciatore et al., 2014). Four of the participants described their help-seeking behavior in going to the church after their grief as one that was immediate and based on a sense of guidance and comfort needed. They felt that this was received by the church and church family as welcoming, as though feeling the "open arms of God" in their grief, gaining to ability to feel calmer and control over the violent death of their family member. Three of the participants described the help-seeking process from the church as one which was natural and peaceful, and even automatic in making the choice to seek help from the church versus reaching out to those traditional mental health resources. Reaching out to the church and their church family was a way that they sought comfort in their times of grief and served as an avenue to God through their pastor; it made them feel complete in the comfort in knowing that "everything would be alright." 


\section{Theme 2: Church Is a Resource for Trust and Relationships}

\section{The Importance of Spiritual and Cultural Competency of Mental Health Counselors and Educators}

One's spiritual or religious beliefs are commonly viewed worldwide; at least $90 \%$ of the United States' population reports being involved in some form of spiritual or religious practice (Sargent et al., 2019). As a next step to understanding the reactions and coping behaviors of African Americans in coping with grief and losing a family member due to violence, researchers suggest applying a theoretical framework that considers the effects of sociocultural influences on grief and coping and focusing on seeking non-clinical help (Wilson et al., 2014). Most participants shared with the researcher that trust for their church, church members and the pastor helped make their choice about where to seek help after the violent death of a family member, and even other life issues. The church served as their safety net and closeness it the members of the church; this light and way through their darkness was gained through the pastor. They trusted their pastor; this trust was built over many generations. The majority of the participants felt that their reasons for seeking the church in grief was because they had a strong sense of trust in the pastor and the church members. They described this sense of trust as one built over many generations.

\section{Theme 3: Relationships with God and the Pastor for Guidance, Direction, and Support}

\section{There is a Possible Link Between the Under-Utilization of Mental Health Resources to Mistrust by the African American Population}

African Americans traditionally turned to their spiritual leaders or family members for guidance, and the church is one place used by African Americans for many resources. The unwillingness of African Americans to go outside of the church for these same resources is common (Avent \& Cashwell, 2015). Perhaps the hesitation of many African Americans to participate more actively in the counseling process, i.e., traditional mental health resources, is rooted in a lack of trust, which has evolved historically from slavery and unethical treatment of African Americans in the United States (Avent \& Cashwell, 2015). Many participants viewed their pastor and the church as a vessel to God, and some as one. African Americans have found the use of coping spiritually as a means of maintaining a connection to deceased family members (Lindinger-Sternart, 2015). The participants' interviews about their described experiences revealed that the church is sought as a means to communicate with God and an established relationship with God. Five of the participants expressed a strong need for guidance from God in their grief process and the church was where their guidance began. Their relationship with God was one which was natural and peaceful, bringing them much joy. They expressed the need for this close relationship from God, a familiar place, unlike a therapist or psychologist. Their relationship with God was one where there were unspoken words, from a relationship built over many generations. This personal connection to God allowed them to cast all of their worries and pain felt in their grief; they were safe.

Seeking the church in grief was an experience described by the participants as a necessary one to make some 'sense' out of the violent death of their family member and a time where they needed a sense of comfort and direction in a time of discomfort and confusion. One participant responded by stating that "African Americans don't call therapists! God is our therapist." All of the participants described the process of seeking the church after the violent death of their family 
member as one which was peaceful and natural, gaining a sense of direction for the unexpected violent death of their family member. It was a thoughtless process, guided by their religion, faith, and spirituality, in their need to communicate to God; this is done through the pastor, the church and church family. Their help-seeking process was one that served to complete and comfort them, knowing that 'everything will be alright.'

\section{Theme 4: Seeking the Church Through Cultural and Familial Traditions}

\section{A Strong Role of the Church as a Grief Resource for African Americans Exists}

The literature on grief and bereavement suggests there are culturally specific perspectives on the management of grief among African American families (Sargent et al., 2019). Grieving patterns of African Americans often include reliance on spiritual, collective, or shared coping resources, and the suppression of emotions to manage one's grief (K. Hays \& Aranda, 2016). The research literature on using religion and spirituality for African Americans indicates that the importance of assisting this population with their coping and resiliency levels regarding daily life stressors. Seven participants interviewed described seeking the church in grief and despair as an automatic thought process and one which did not result from conscious or prolonged thought. The participants described their positions about deciding to seek the church as one which was included a long history of spiritual connectivity to their culture. Eight of the participants noted the church seeking behaviors of African Americans over many generations, even back to the times of slavery, watching their moms, grandparents, and fathers kneel in prayer in many times of difficulty. Sunday morning church-going practices became rituals in the African American family. Trust was important part of the help-seeking process for eight of the participants, as they acknowledged that African Americans trust people that 'look like us'. The church family was seen as their 'village' and a connection to God as their vessel of strength, in sadness, grief and despair.

\section{Discussion}

Few studies have been conducted on how prayer, pastoral counseling, or seeking the church are used for coping skills and resilience by African Americans (Cacciatore et al., 2014; Gaston et al., 2016). For years the churches have had important roles as community support systems for African Americans (Avent \& Cashwell, 2015; Banerjee \& Canda, 2009; Cai \& Robst, 2016). Religion and spirituality do not indicate how this loss is experienced by the African American adult and the extent religion and spirituality play in these more extenuating circumstances. These treatment issues are also important to pastors, as they seek to understand the important role their church plays in the mental health of their parishioners, as well as potential barriers to clinical help-seeking behaviors. African Americans have found the use of coping spiritually as a means of maintaining a connection to deceased family members (Avent \& Cashwell, 2015). Previous research has indicated that instead of formal mental health service providers, African Americans tend to rely on more informal sources of support in grief, such as church and church family (Cai \& Robst, 2016; Chatters, Taylor, Woodward, \& Nicklett, 2015; K. Hays \& Aranda, 2016; Holt et al., 2017; Jones et al., 2018). Ninety-two percent of African Americans indicate that religion and church attendance is very important to them and that they are hesitant to seek mental health providers for their mental health issues; for example, grief, because therapy would take away from their religious beliefs (Chatters, Taylor, Woodard, et al., 2015). 
Several themes emerged after thematic analysis of the data:

- Theme 1: Church Is Guidance Through Religion/Spirituality in Grief - for Comfort and Coping

- Theme 2: Church Is a Resource for Trust and Relationships

- Theme 3: Relationships with God and the Pastor for Guidance, Direction, and Support

- Theme 4: Seeking the Church Through Cultural and Familial Traditions

All four themes were interrelated as a result of the thematic analysis process. Many participants interviewed for this study indicated that their families have sought the use of the church in their psychological first aid for coping and resilience. For example, individual prayer, pastoral counseling, or other non-clinical mental health resources. Many of these African American adults' interviews also attributed their sense of connectedness to the church to their personal psychological preservation of how they view the church, as well as the connectedness they received. The conclusions are integrated in Pargament's theory of religious coping as the described experiences of seeking the church for comfort after the violent death of a family member and described as deeply entrenched in religion and coping and each participant considered the importance in their religion and spirituality in determining their mental health help-seeking behaviors; they each emphasized the noteworthiness in manners identified with the holy (Xu, 2016). As emphasized in Pargament's theory of religious coping, their involvement in religion, in coping with grief, and discovering affordable ways to understand and deal with the negative events and feelings related to grief, all served as a sense of significance during the time of their grief (Chandler, 2020; Xu, 2016); it was not be viewed as a defense mechanism, but was active and involved dynamically in every stage of their grief coping process (Abu-Raiya \& Pargament, 2015; Xu, 2016).

\section{Limitations}

Examining and noting the limitations of research is an important component in conducting research (Hackett, 2014). These limitations not only address constraints encountered while conducting the research, but the process of noting limitations also facilitates the opportunity for the researcher to replicate and eliminate any barriers which may have restricted the research in some way (Hackett, 2014). Limitations identified for this study included recruiting participants from only one specific church, only including African American adults as participants, studying participants from the perspective of only one religious belief, focusing on African American adult who had never sought professional help after a family member's violent death, and using a small sample size.

\section{Recommendations for Further Research}

Continued future research on the mental health help-seeking behaviors of African American adults is important to the counseling and counseling education professions. While the study has provided important findings in gaining a clearer insight into the self-defined religious African American adult who seeks the church for support after the violent death of a family member, there is more to be examined. Further research topics recommended are examining the spiritual distress in bereavement, help-seeking behaviors amongst differing cultures, collaboration efforts of church pastors and mental health professionals in addressing the mental 
health issues of African Americans, and gender differences in the help-seeking behaviors of African Americans, as a whole.

The literature has suggested that many mental health professionals lump the religious experiences of African American clients into a homogeneous mass, instead of individualizing their described religious experiences and consideration of the vast orientations of religion in which African Americans have (Bell-Tolliver \& Wilkerson, 2014; Sargent et al., 2019). Findings from this study have provided mental health professionals, counselor educators, and supervisors with resources for changes and educate counselors on the importance of incorporating spiritual resources into the counseling session when working with African American clients, as well as increasing the spiritual and cultural competencies of this profession (Chandler, 2020; Holt et al., 2017; Smith, 2013). The time is now for continuing to build the levels of spiritual and cultural competency in the mental health field for understanding the important role of spirituality and religion in the work we do serving African Americans and other global diverse communities across the world.

\section{Author Reflections}

This topic was important to me, as a religious/spiritual African American woman, and a licensed professional counselor and counseling educator. I recognized the mental need to address the help-seeking disparities that continue to exist. Findings from my research substantiates the importance for mental health professionals to increase their levels of cultural and spiritual competencies in serving the African American community and global communities. It is particularly important for mental health professionals who serve the African American community and other global communities to examine this help-seeking process in the time of grief. As a licensed professional counselor, through clinical training, experience, and education, I know that one's spirituality and religion does not heal depression or any other mental health disorder. I do, however, believe that it is important to integrate spirituality and religion into the therapeutic process for those who have adopted these beliefs. It is important to understand how this experience of choice, and its description, evolves in the minds of African American adults, in past generations and now in the present, who seek help in the church and church family after experiencing grief and loss, particularly in the midst of violence.

\section{Funding}

The research for this article was funded solely by the author.

\section{Acknowledgments}

Acknowledgment is given to Bishop Jones and all the participants of this study in creating a clearer insight into the experience of African Americans who choose to seek the church, versus traditional mental health resources, guided by their faith, religion, and spirituality.

\section{References}

Abu-Raiya, H., \& Pargament, K. I. (2015). Religious coping among diverse religious: Commonalities and divergences. Psychology of Religion and Spirituality, 7(1), 24-33. https://doi.org/10.1037/a0037652

American Psychiatric Association. (2017). Mental health disparities: African Americans. https://doi.org/10.1891/9780826103680.0009 
Avent, J., \& Cashwell, C. S. (2015). The Black church: Theology and implications for counseling. The Professional Counselor, 5(1), 81-90. https://doi.org/10.15241/jra.5.1.81

Banerjee, M. M., \& Canda, E. R. (2009). Spirituality as strength of African American women affected by welfare reform. Journal of Religion \& Spirituality in Social Work, 28(3), 239-262. https://doi.org/10.1080/15426430903070194

Bell-Tolliver, L., \& Wilkerson, P. (2014). The use of spirituality and kinship as contributors to successful therapy outcomes with African American families. Journal of Religion \& Spirituality in Social Work: Social Thought, 30(3), 48-70.

https://doi.org/10.1080/15426432.2011.542723

Cacciatore, J., Lacasse, J. R., Lietz, C. A., \& McPherson, J. (2014). A parent's tears: Primary results from the traumatic experiences and resilience study. OMEGA: Journal of Death \& Dying, 68(4), 183-205. https://doi.org/10.2190/om.68.3.a

Cai, A., \& Robst, J. (2016). The relationship between race/ethnicity and the perceived experience of mental health. American Journal of Orthopsychiatry, 86(5), 508-518. https://doi.org/10.1037/ort0000119

Chandler, D. M. (2020). African American Spirituality, Grief \& Mental Health: Seeking the Church After a Family Member's Violent Death [Doctoral dissertation, Capella University, Minneapolis, MN]. ProQuest Dissertations Publishing.

Chaney, C. (2015). Who is David and who is Goliath? The Eddie Long scandal and the Black mega-church. Mental Health, Religion, and Culture, 16(2), 58-61. https://doi.org/10.1080/13674676.2011.645224

Chatters, L. M., Taylor, R. J., Lincoln, K. D., Nguyen, A., \& Joe, S. (2015). Church based social support and suicidality among African American and Black Caribbean's. Archives of Suicide Research, 15(4), 337-353. https://doi.org/10.1080/13811118.2011.615703

Chatters, L. M., Taylor, R. J., Woodward, A. T., \& Nicklett, E. J. (2015). Social support from church and family members and depressive symptoms among older African Americans. American Journal of Geriatric Psychiatry, 23(6), 559-567. https://doi.org/10.1016/j.jagp.2014.04.008

Cunningham, S. R., Schumacher, J. A., \& Bell-Neasman, T. P. (2018). Reactions to violence among African American female survivors of intimate partner victimization. Journal of Black Studies, 49(5), 502-519. https://doi.org/10.1177/0021934718770825

Dalencour, M., Wong, E. C., Tang, L., Dixon, E., Lucas-Wright, A., Wells, K., \& Miranda, J. (2017). The role of faith-based organizations in the depression care of African Americans and Latinos in Los Angeles. Psychiatric Services, 68(4), 368-374. https://doi.org/10.1176/appi.ps.201500318

Fripp, J. A., \& Carlson, R. G. (2017). Exploring the influence of attitude and sigma on participation of African American and Latino populations in mental health services. Journal of Multicultural Counseling and Development, 45(2), 80-94. https://doi.org/10.1002/jmcd.12066 
Gaston, G. B., Earl, T. R., Nisanci, A., \& Glomb, B. (2016). Perception of mental health services among Black Americans. Social Work in Mental Health, 14(6), 676-695. https://doi.org/10.1080/15332985.2015.1137257

Gonzalez, J. M., Alegría, M., Prihoda, T. J., Copeland, L. A., \& Zeber, J. E. (2009). How the relationship of attitudes toward mental health treatment and service use differs by age, gender, ethnicity/race and education. Social Psychiatry and Psychiatric Epidemiology, 46(1), 45-57. https://doi.org/10.1007/s00127-009-0168-4

Hackett, J. R. (2014). Mental health in the African American community and the impact of historical trauma systematic barriers. Retrieved from https://sophia.stkate.edu/msw_papers/320

Hays, K., \& Aranda, M. P. (2016). Faith-based health interventions with African Americans: A review. Research on Social Work Practice, 26(7), 777-789. https://doi.org/10.1177/1049731515569356

Hays, K., \& Lincoln, K. D. (2017). Mental health help-seeking profiles among African Americans: Exploring the influence of religion. Race and Social Problems, 9(2), 127138. https://doi.org/10.1007/s12552-017-9193-1

Holt, C. L., Roth, D. L., Huang, J., Park, C. L., \& Clark, E. M. (2017). Longitudinal effects of religious involvement on religious coping and health behaviors in a national sample of African Americans. Social Science \& Medicine, 187, 11-19 https://doi.org/10.1016/j.socscimed.2017.06.014

Johnson, K., Elbert-Avila, K., \& Tulsky, J. (2015). The influence of spiritual beliefs and practices on the treatment preference of African Americans. A review of literature. Journal of American Geriatrics Society, 53(4), 711-719. https://doi.org/10.1111/j.15325415.2005.53224.x

Johnson, S. D., Williams, S. L., \& Pickard, J. G. (2016). Trauma, religion and social support among African American women. https://www.nacsw.org/RC/49996633.pdf\#page=64

Jones, M. K., Buque, M., \& Miville, M. L. (2018). African American gender roles: A content analysis of empirical research from 1981 to 2017. Journal of Black Psychology, 44(5), 450-486. https://doi.org/10.1177/0095798418783561

Katz, A. D., \& Hoyt, W. T. (2014). The influence of multicultural counseling competence and anti-Black prejudice on therapists' outcome expectancies. Journal of Counseling Psychology, 61(2), 299-305. https://doi.org/10.1037/a0036134

Lindinger-Sternart, S. (2015). Help-seeking behaviors of men for mental health and the impact of diverse cultural backgrounds. International Journal of Social Science Studies, 3(1), 1-6. https://doi.org/10.11114/ijsss.v3i1.519

Morrison, K. S., \& Hopkins, R. (2019). Cultural identity, africultural coping strategies, and depression as predictors of suicidal ideations and attempts among African American female college students. Journal of Black Psychology, 45(1), 3-25. https://doi.org/10.1177/0095798418813511 
National Alliance on Mental Illness. (2018). African American mental health. https://www.nami.org/find-support/diverse-communities/african-americans

Park, C. L., Holt, C. L., Le, D., Christie, J., \& Williams, B. R. (2018). Positive and negative religious coping styles as prospective predictors of well-being in African Americans. Psychology of Religion and Spirituality, 10(4), 318-326. https://doi.org/10.1037/rel0000124

Robinson, M. A., Jones-Eversley, S. J., Moore, S. E., Ravenell, J., \& Adedoyin, A. C. (2018). Black male mental health and the Black church: Advancing a collaborative partnership and research agenda. Journal of Religion and Health, 57(3), 899-909. https://doi.org/10.1007/s10943-018-0570-X

Sargent, E., Zahniser, E., Gaylord-Harden, N., Morency, M., \& Jenkins, E. (2019). Examining the effects of family and community violence on African American adolescents: The roles of violence type and relationship proximity to violence. The Journal of Early Adolescence, 27(2), 619-858. https://doi.org/10.1177/0272431619858397

Skloot, R. (2015). The immortal life of Henrietta Lacks. United States of America: Omar A. Quintero.

Smith, T. (2013). What is evidence-based behavior analysis? The Behavior Analyst, 36(2), 7-33. doi:10.1007/BF03392290

Turner, N., Hastings, J. F., \& Neighbors, H. W. (2019). Mental health care treatment seeking among African Americans and Caribbean Blacks: What is the role of religiosity/spirituality? Aging \& Mental Health, 23, 905-911. https://doi.org/10.1080/13607863.2018.1453484

VanderWeele, T. J., Yu, J., Cozier, Y. C., Wise, L., Argentieri, M. A., Rosenberg, L, Palmer, J. R., \& Shields, A. E. (2017). Attendance at religious services, prayer, religious coping, and religious/spiritual identity as predictors of all-cause mortality in the Black women's health study. American Journal of Epidemiology, 185(7), 515-522. https://doi.org/10.1093/aje/kww179

Watlington, C. G., \& Murphy, C. M. (2016). The roles of religion and spirituality among African American survivors of domestic violence. Journal of Clinical Psychology, 62(70), 837857. https://doi.org/10.1002/jclp.20268

Wilson, C. K., Lamis, D. A., Tarantino, N., Lansford, J. E., \& Kaslow, N. J. (2014). Neighborhood disorder, spiritual well-being, and parenting stress in African American women. Journal of Family Psychology, 28(6), 769-778. https://doi.org/10.1037/a0036373

$\mathrm{Xu}$, J. (2016). Pargament's theory of religious coping: Implications for spiritually sensitive practice. British Journal of Social Work, 46(2), 1394-1410. https://doi.org/10.1093/bjsw/bcv080 


\section{Appendix A}

Question 1 - Describe your experience with the events that surrounded the death of your family member.

Question 2-What were your motivations for seeking help from the church after your family member's death?

Question 3 - Describe your experience with the church after the loss of your family member.

Question 4 - Describe, in detail, your experience with grief after seeking the church due to the loss of your family member.

Question 5 - Describe any outcomes you experienced after seeking the church due to the loss of your family member. 


\section{Appendix B}

The researcher screened participants with the following questions:

1. Do you have a personal connection with the researcher? (NO)

2. Are you African American and 18 yrs. of age or older? (YES)

3. Do you self-define as spiritual or religious? (YES)

4. Have you lost a family member due to violence? (YES)

5. Have you sought help from the church after the death of a family member by violence? (YES)

6. Has it been less than five years since the death of a family member by violence? (NO)

7. Are you currently in mental health therapy? (NO)

8. Have you sought help from a clinical mental health professional after the death of a family member by violence? (NO) 